\title{
Atrial fibrillation: A review of modifiable risk factors and preventive strategies
}

\author{
ALIREZA SEPEHRI SHAMLOO, NIKOLAOS DAGRES, ARASH ARYA, GERHARD HINDRICKS \\ Department of Electrophysiology, Heart Center Leipzig, Germany
}

\begin{abstract}
Atrial fibrillation (AF), as the most common cardiac arrhythmia worldwide, is associated with increased mortality and morbidity. Successful therapeutic strategies have been introduced so far, but they are associated with significant costs. Therefore, identification of modifiable risk factors of AF and the development of appropriate preventive strategies may play a substantial role in promoting community health and reducing health care system costs. Modifiable cardiovascular risk factors including obesity, hypertension, diabetes mellitus, obstructive sleep apnea, alcohol consumption, smoking, and sedentary lifestyles have been proposed as possible contributors to the development and progression of AF. In this review, we discuss the role of modifiable risk factors in the development and management of $\mathrm{AF}$ and the evidence for the underlying mechanism for each of the potential risk factor.
\end{abstract}

Key words: Atrial fibrillation, risk factors, lifestyle modification, prevention, treatment, physiopathology.

\section{INTRODUCTION}

Atrial fibrillation (AF), as the most common cardiac arrhythmia worldwide, is estimated to affect almost 18 million people in Europe by $2060[1,2]$ and poses a significant burden to the healthcare systems [3, 4]. AF is associated with increased mortality and morbidities such as stroke and dementia [5-8]. Successful therapeutic strategies have been introduced such as oral anticoagulation, pharmacological rate control as well as pharmacologic or electrical cardioversion, antiarrhythmic drugs and catheter ablation for rhythm control; however they are associated with significant costs [9-14]. The increasing age of the population, and in parallel the increasing prevalence of the risk factors for development of AF, have strengthened the hypothesis of the epidemic emergence of $\mathrm{AF}$ in the coming decades [15]. Therefore, identification of probable modifiable risk factors of $\mathrm{AF}$ and the development of appropriate preventive strategies, mainly in high-risk patients, may play a substantial role in promoting community health and reducing health care system costs [1].

Modifiable cardiovascular risk factors including obesity, hypertension (HTN), diabetes mellitus, obstructive sleep apnea (OSA), alcohol consumption, smoking, and sedentary lifestyles have been proposed as possible contributors to the development and progression of $\mathrm{AF}$ [7, 16-19]. In contrast, the evidence for the association of some other cardio- vascular risk factors such as dyslipidemia with $\mathrm{AF}$ is less robust [20]. In this review, we discuss the role of modifiable risk factors in the development and management of $\mathrm{AF}$ and the evidence for the underlying mechanism for each of the potential risk factors associated with $\mathrm{AF}$.

\section{Obesity}

Multiple epidemiological studies have demonstrated a strong and independent relationship between obesity and $\mathrm{AF}$ in recent years [17, 21]. The Framingham Heart Study reported that each unit increase in body mass index (BMI) was associated with 4 to $5 \%$ increased risk of incident $\mathrm{AF}$, independent of other comorbidities such as acute myocardial infarction, diabetes and HTN [22]. Moreover, the ARIC study reported that a BMI higher than $25 \mathrm{~kg} / \mathrm{m}^{2}$ (as a definition for overweight and obesity) accounted for approx. $18 \%$ of cases of incident AF [23]. A recent meta-analysis showed per 5 units increment in BMI, risk of AF increased by around 1.3 times [24]. Another metaanalysis on 587,372 subjects confirmed a higher incidence of $\mathrm{AF}$ in obese individuals in comparison with non-obese ones (6.3\% versus $3.1 \%$; RR $($ Relative Risk $)=1.51)$ [25]. Besides, other studies have indicated that patients with $\mathrm{BMI} \geq 35 \mathrm{~kg} / \mathrm{m}^{2}$ had a higher rate of post-ablation $\mathrm{AF}$ recurrence compared with those with BMI $<35 \mathrm{~kg} / \mathrm{m}^{2} \mathrm{HR}$ $($ Hazard Ratio $)=1.22)$ [26]. 
Although the association between obesity and $\mathrm{AF}$ appears to be confirmed, the evidence regarding the effect of weight loss on the AF outcomes is more limited. However, it seems that weight loss might be beneficial in terms of a lower AF risk through indirect ways, by its impact on blood pressure, insulin resistance, and sleep disorders [27]. Results from the LEGACY study in patients with AF showed that weight loss sustained in the long term was associated with a significant reduction of AF development. Their results indicated that more than $10 \%$ weight loss resulted in a 6 -fold more chance of arrhythmia-free survival in comparison to $<9 \%$ weight loss [28].

The association between $\mathrm{AF}$ and obesity seems to be multifactorial. Left atrial (LA) enlargement due to obesity is considered an important underlying precursor of AF [29]. Moreover, a slower LA conduction time, as well as shorter effective refractory periods in both LA and pulmonary veins, have been reported in patients with higher BMI [30]. Also, a higher amount of pericardial and epicardial fat tissues in obese subjects, which seem to play a significant role in promoting arrhythmogenesis due to their pro-inflammatory properties, are further possible mechanisms [31, 32]. Furthermore, obstructive sleep apnea and hypertension, which are considered to be associated with obesity, are deemed as other indirect mechanisms for obesity-induced AF [21].

\section{Hypertension}

HTN has long been recognized as one of the major risk factors for cardiac arrhythmias, particularly AF [33]. Most of the studies investigating the association between $\mathrm{HTN}$ and AF reported a high prevalence rate of HTN, ranging from 50 to $90 \%$, in patients with AF [34]. Not only HTN (systolic blood pressure (SBP) $\geq$ $130 \mathrm{mmHg}$ ), but also pre-HTN (SBP 120$129 \mathrm{mmHg}$ ) have been shown to increase the risk of incident AF by 2.6 and 1.8 times, respectively [28]. According to the Framingham Heart Study, both borderline SBP and stage II-IV (SBP $>160 \mathrm{mmHg}$ and diastolic $\mathrm{BP}>95 \mathrm{mmHg}$ ) were associated with an increased risk of $\mathrm{AF}$ (OR for men $=1.5$ and for women $=1.4$ ) [35].

Interestingly, recent evidence supports the idea that optimal treatment of HTN may be effective in AF prevention; however, the best HTN treatment strategy leading to the best AF outcome is less conclusive [36]. Results of the ARREST-AF study indicated that poorer control of HTN was associated with a higher rate of $\mathrm{AF}$ recurrence after ablation (HR 1.3; p < 0.02) [37]. A large metaanalysis with a pooled sample size of 56,308 subjects revealed that angiotensin-converting enzyme inhibitors (ACEi) and angiotensin II receptor blockers (ARBs) could decrease the relative risk of AF by almost one-third [38].

Extensive LA remodeling, which contributes to the substrate for $\mathrm{AF}$, is a well-established mechanism for hypertension-induced AF [39]. Left ventricular (LV) hypertrophy as well as impaired diastolic dysfunction are further pathophysiological features of chronic HTN which are related to the occurrence of AF [40]. Moreover, global conduction slowing and regionally delayed conduction, mainly in the crista terminalis have been demonstrated in patients with chronic HTN [41].

\section{Diabetes}

The association between diabetes as well as elevated blood glucose levels and incident AF has been demonstrated in various studies [42]. In a nationwide cohort study, the youngest diabetic patients had a more than 2-fold increased AF risk, and diabetes was independently associated with developing AF [43]. Similarly, results from another study showed that diabetes type II increased the risk for new-onset AF by 1.5 fold, irrespective of other coexisting comorbidities [44]. Moreover, it has been argued that per additional year of diabetes, the estimated risk of AF could increase by 3\% [45]. A recently conducted meta-analysis showed that prediabetes and diabetes increase the AF risk by $20 \%$ and $28 \%$ respectively, with a dose-response relationship between increasing blood glucose and $\mathrm{AF}$ [46]. In another meta-analysis, patients with diabetes showed $39 \%$ greater risk of incident $\mathrm{AF}$ compared with the control group [42]. However, the impact of intense glycaemic control (IGC) on the incidence and recurrence of $\mathrm{AF}$ is not clear yet [47]. In the Action to Control Cardiovascular Risk in Diabetes (ACCORD) trial, non-intense glycaemic control (HbA1c: 7.0-7.9\%) was not inferior in preventing new $\mathrm{AF}$ in comparison with IGC $(\mathrm{HbA} 1 \mathrm{c}<6.0 \%)[48]$.

Insulin resistance, oxidative stress, connexin remodeling, and glycaemic fluctuations, as well as autonomic, electrical, electromechanical and structural remodeling, are among the most well established pathophysiological mechanisms for diabetes-induced AF [49]. Other mechanisms such as prolonged intraatrial conduction time and diffuse interstitial fibrosis were investigated as possible triggers of increased arrhythmogenicity in diabetes in animal models [40]. 


\section{Diet}

Fish and omega-3 polyunsaturated fatty acids (PUFAs) have been suggested by some studies to lower AF risk; although the results seem inconsistent [50]. A pooled analysis of two prospective studies including the Cohort of Swedish Men and the Swedish Mammography Cohort did not support a beneficial impact of PUFAs or fatty fish intake on incident AF [51]. However, a single randomized controlled trial (RCT) reported that the Mediterranean diet with olive oil may decrease AF risk by approx. 40\% (HR 0.62; 95\% confidence interval: $0.45-0.85)$ [52].

Chocolate intake was first introduced as a protective factor for AF [53]; however, results from a recently meta-analysis with a pooled population of 180,454 participants and 16,356 AF cases showed no significant difference in AF rate between participants with the highest chocolate intake compared with the lowest category of chocolate intake (HR $=0.95 ; 95 \%$ CI: 0.90-1.03) [54]. In a large population-based cohort study on 57,053 participants, coffee consumption was also shown to be associated with a lower rate of AF risk [55].

It seems that data about the association between a specific dietary approach and AF risk is still largely lacking, and more evidence is required for drawing sound conclusions [52].

\section{Alcohol consumption}

Acute alcohol intake is a well cause of AF, described with the term "Holiday Heart" [27]. Most observational studies have established a significant association between high levels of alcohol consumption and AF. However, the beneficial effects of mild-moderate alcohol intake is a matter of question yet [56]. According to the Framingham Heart Study, heavy alcohol intake of more than three drinks per day ( $>36 \mathrm{~g}$ alcohol/day) was significantly associated with a greater risk of incident AF [57]. Moreover, a meta-analysis on 859,420 participants showed a linear association between alcohol intake and incident AF over 12 years of follow-up [58]. In addition, results from a recently conducted meta-analysis revealed that although low levels of alcohol intake were not associated with the AF development, moderate and high alcohol intake were associated with a heightened AF risk [27]. Underestimation of alcohol consumption may be a major limitation in the different studies, since in most of them the quantities of alcohol intake were typically self-reported by the participants. So, it seems that there might be no safe level of chronic alcohol intake regarding AF development. Nevertheless, the impact of alcohol consumption and cessation on post-ablation $\mathrm{AF}$ recurrence seems not clear yet. Molecular remodeling, fibrosis, electrophysiologic characteristics that favor re-entry, and lastly association of alcohol intake with the incidence of other AF risk factors have been introduced as the possible mechanism [21].

\section{Smoking}

Smoking is considered a major risk factor for AF development and has been reported as a component in several risk prediction models [59]. Smoking is not only an important parameter for identification of patients at high risk of $\mathrm{AF}$, but also a factor that increases the risk of thromboembolic events following an AF diagnosis [60, 61]. Data from large cohort studies showed that both former and current smoking were equally associated with increased AF risk [62]. Also, results from a recent meta-analysis confirmed that smoking was associated with an increased risk of AF in a dosedependent manner; however, this association was weaker among former smokers compared to current smokers [63]. That meta-analysis highlighted a possible dose-dependent increase in risk; longer duration of smoking and a higher number of cigarettes per day might lead to a higher risk of AF [63]. Importantly, secondhand tobacco exposure, as well as exposure during gestational development, have also been associated with risk of AF [64, 65]. So it seems that smoking cessation should be recommended not only as a proven risk factor of many other cardiovascular disorders, but also as a risk factor for AF; however, data on post-ablation AF recurrence are still lacking. The good news is that a reduction of around 36\% in AF risk has been reported in patients who were able to quit smoking [66].

Different direct and indirect mechanisms (including increased myocardial ischemia, reduced lung function) have been evoked to explain the association between smoking and incident AF [40]. The increased volume of atrial fibrosis, as well as increased AF susceptibility caused by the duration of the action potential (APD) prolongation are two major direct mechanisms [67].

\section{Dyslipidemia}

The role of dyslipidemia, as a significant risk factor for cardiovascular diseases, in AF is not fully understood as a result of limited evidence. Although 
most of the studies showed inverse associations between AF and every $10-50 \mathrm{mg} / \mathrm{dL}$ increase in total cholesterol or low-density lipoprotein (LDL), or total cholesterol $\geq 220-280 \mathrm{mg} / \mathrm{dL}$ or $\mathrm{LDL} \geq 150 \mathrm{mg} / \mathrm{dL}$, in some studies, this association was not significant [20]. Moreover, results for high-density lipoprotein cholesterol (HDL) and triglycerides (TG) are more heterogeneous; while some of the studies have shown inverse associations, others have revealed direct or null and/or mixed associations [20]. In a pooled dataset from the Framingham Heart Study and the Multi-ethnic Study of Atherosclerosis (MESA), there was no association between LDL levels and AF. However, higher levels of cholesterol and HDL, as well as lower levels of TG, were associated with lower risk of AF [34]. In contrast, the Kailuan Study showed an inverse association of total cholesterol, and LDL levels with incident AF after a follow-up period of 7.12 years on 88,785 participants, while no significant association was observed between TG or HDL levels and AF [61]. In another study on 28,449 individuals, low HDL was related to an increased AF risk in women $(\mathrm{HR}=$ 2.86), but not in men $(\mathrm{HR}=1.35)$ [68]. The beneficial impact of lipid-lowering therapy in the secondary prevention of AF is a further matter of debate. Although statin therapy has been shown to be beneficial in reducing AF risk as a secondary prevention, the evidence for a role in primary prevention of AF is still insufficient $[69,70]$.

\section{Physical Activity}

Recent evidence shows that a non-sedentary lifestyle activity plays a protective factor with regard to AF occurrence; however, extreme and prolonged exercise itself can be considered a risk factor for $\mathrm{AF}$ [71, 72]. In the majority of population-based studies, mild to moderate physical activity was associated with a decreased AF risk, whereas only few studies failed to show an association between exercise and AF [73, 74]. It has been suggested that daily walking or cycling might lead to a risk reduction of AF by about $20 \%$ [75]. In the Cardiovascular Health Study, the incidence of $\mathrm{AF}$ in older individuals with more regular physical activity was reported to be around $50 \%$ lower than those with less activity [76]. Moreover, results from two Asian studies showed that moderate physical activity was a protective factor for AF [77, 78].

A recent meta-analysis indicated a $\mathrm{J}$-shaped pattern for the association between risk of AF and extent of exercise [79]. Other studies also reported that athletes are about two to five times more likely to have AF than the non-athletes [80]. Thus, according to the available evidence, it seems that the level of physical activity and risk of AF have a nonlinear relationship. Both sedentary lifestyle and very extreme exercise appear to be possible triggers for AF development, mainly in young men. However, the effect of different types of sports, as well as their durations and frequencies on $\mathrm{AF}$ is a matter of question yet.

Although no precise mechanism for the increased AF risk among athletes with severe physical activity has been identified yet, some important pathways for the underlying pathophysiology have been proposed. Elevated autonomic activity, atrial dilatation, and fibrosis, abrupt shifts between vagal dominance and sympathetic drive are among the suggested mechanisms for increasing the risk of $\mathrm{AF}$ following endurance sports [81, 82]. In contrast, improving systolic and diastolic function, lowering sympathetic drive, as well as reducing arterial stiffness are the proposed mechanisms for the beneficial effects of physical activity on AF risk reduction $[83,84]$.

\section{Sleep disorders}

In most of the conducted studies, a significant association has been observed between sleep disorders and AF risk (RR range of 1.26-2.51) [85]. A recent meta-analysis reported that sleep disorders increased the risk of AF significantly $(R R=1.70)$, and higher severity of sleep disorders was associated with a higher AF risk [86]. Moreover, another meta-analysis confirmed that the risk of AF was greater among patients with sleep disorders compared with the control group OR (Olds ratio) $=2.1$ [87]. Further studies highlighted that different types of sleep disorders might have different impacts on the AF incidence [88]. In a large multiethnic study on 2048 participants, AF was more frequent in patients with poorer sleep quality [89]. Interestingly, ethnicity was recently introduced as an important factor in the association between sleep disorders and AF with a higher risk of AF in black individuals with sleep disorders [90].

A role of sleep disorders in the development of post-ablation AF recurrence has also been indicated in a recent meta-analysis [91]. The beneficial effect of continuous positive airway pressure device (CPAP) treatment has also been demonstrated in reducing the rate of $\mathrm{AF}$ recurrence after ablation [91]. However, the efficacy of any therapeutic intervention for patients with sleep disorders in 
decreasing the new-onset $\mathrm{AF}$ risk is not well understood. Multiple factors have been introduced as possible pathophysiologic mechanisms of sleep disorders-induced AF, including hypercapnic hypoxia, changes in intrathoracic pressure increased ganglionated plexi activity, structural and electrical remodeling, and reduced atrial effective refractory period (ERP) [92, 93].

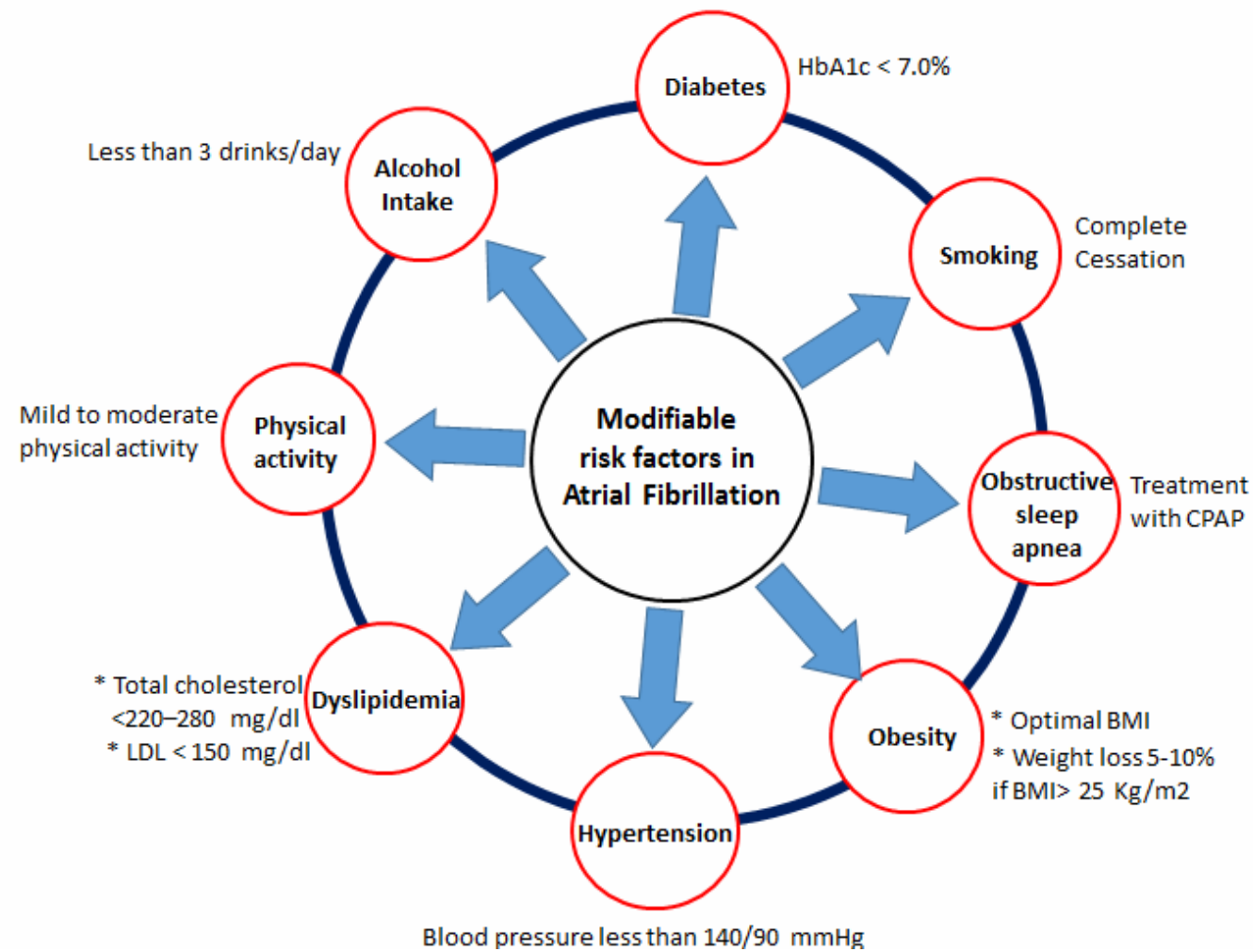

Figure 1. Risk factor management strategies in atrial fibrillation and treatment goals.

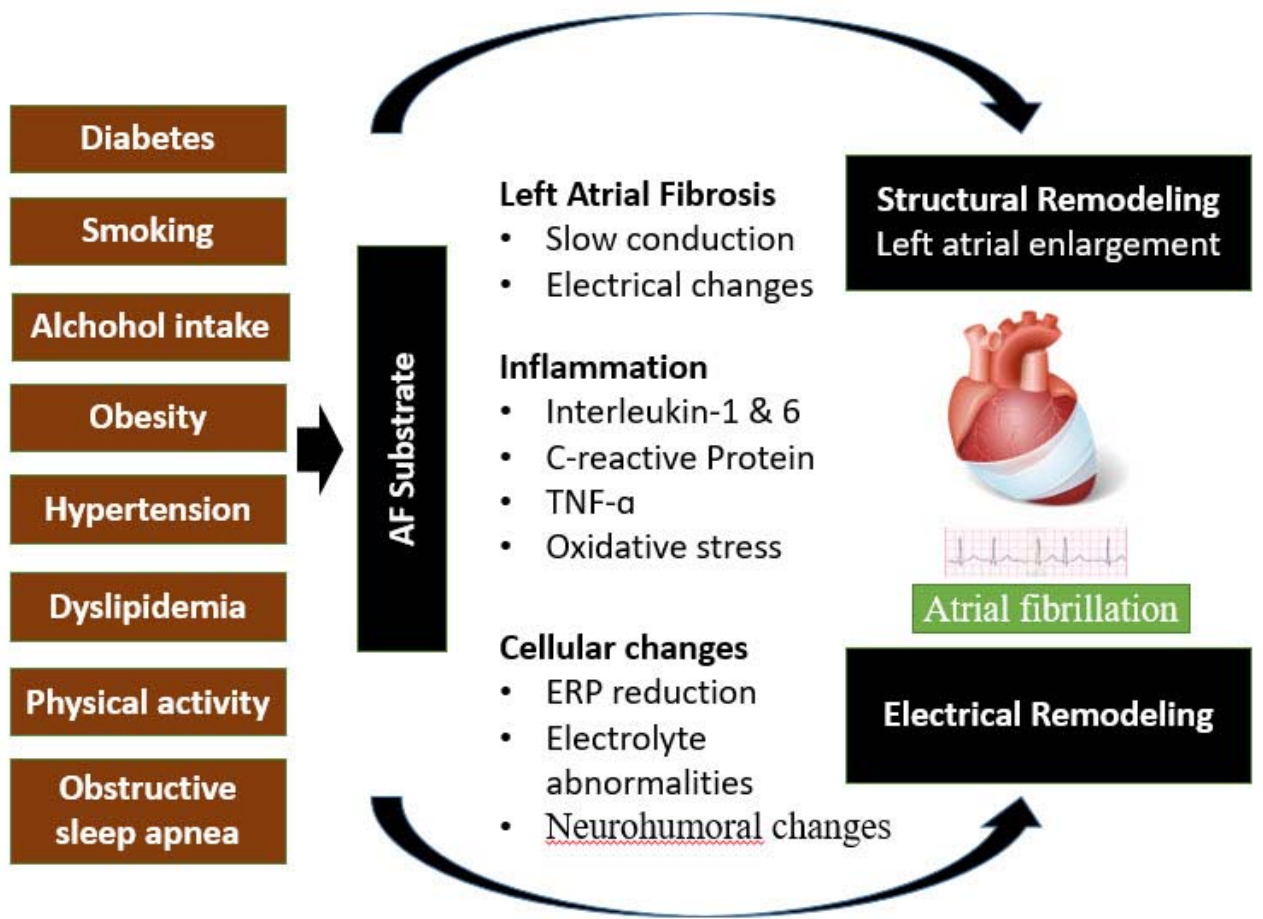

* Please note that the evidence supporting the effectiveness in AF prevention and in particular the therapeutic targets is limited.

Figure 2. Different possible mechanisms through which modifiable risk factors may contribute to atrial fibrillation (AF). 


\section{CONCLUSIONS}

It seems that most of the suggested modifiable risk factors of AF including obesity, hypertension, diabetes, smoking, and the beneficial effects of their primary and secondary preventions are common with cardiovascular diseases risk factors. However, the evidence for the efficacy of optimal control of these risk factors by dyslipidemia management, glycaemic control, optimal antihypertensive treatment, physical activity, and alcohol cessation in improving AF outcomes is less evident. Similarly, although a higher prevalence of AF in patients with sleep disorders seems undeniable, the efficacy of therapeutic interventions for decreasing the risk of new-onset AF is not clear yet. Nevertheless, avoiding a sedentary lifestyle or vigorous exercise may contribute to prevention of AF onset, especially in young men. Considering the association between obesity and other AF risk factors such as HTN, diabetes, and sleep disorders, weight loss appears to play a significant role in the prevention of new and recurrent AF.

Declaration of interest: G.H. and N.D. report research grants from Abbott, Biotronik, Boston Scientific and Medtronic to the institution without personal financial benefits.

Acknowledgments: None.

Fibrilația atrială $(A F)$ este cea mai frecventă aritmie în întreaga lume şi este asociată cu o mortalitate şi morbiditate importantă. Strategiile terapeutice au fost introduse însă ele sunt costisitoare. Aşadar identificarea factorilor de risc modificabili ar putea juca un rol important în scăderea acestor costuri. Factorii modificabili sunt reprezentați de obezitate, hipertensiunea arterială, diabetul zaharat, apneea în somn, consumul de alcool, fumatul şi stilul de viață sedentar. In acest articol este discutat rolul pe care aceşti factori de risc modificabili îl joacă în dezvoltarea şi managementul fibrilației atriale precum şi nivelul de evidență legat de mecanismul implicării fiecăruia dintre aceşti factori de risc.

Correspondence to: Alireza Sepehri Shamloo, M.D., Department of Electrophysiology,

Heart Center Leipzig at University of Leipzig, Strümpellstrasse 39, 04289 Leipzig, Germany

Tel: +49 3418651413 ; Fax: +493418651460

E-mail: sepehria871@gmail.com

\section{REFERENCES}

1. KIRCHHOF P, BREITHARDT G, BAX J, BENNINGER G, BLOMSTROM-LUNDQVIST C, BORIANI G et al. A roadmap to improve the quality of atrial fibrillation management: Proceedings from the fifth Atrial Fibrillation Network/European Heart Rhythm Association consensus conference. Europace: European pacing, arrhythmias, and cardiac electrophysiology. Journal of the working groups on cardiac pacing, arrhythmias, and cardiac cellular electrophysiology of the European Society of Cardiology. 2016;18(1):37-50. doi:10.1093/europace/euv304.

2. HONG KL, GLOVER BM. The impact of lifestyle intervention on atrial fibrillation. Current opinion in cardiology. 2018;33(1):14-9.

3. RAATIKAINEN MJ, ARNAR DO, MERKELY B, CAMM AJ, HINDRICKS G. Access to and clinical use of cardiac implantable electronic devices and interventional electrophysiological procedures in the European Society of Cardiology Countries: 2016 Report from the European Heart Rhythm Association. Europace: European pacing, arrhythmias, and cardiac electrophysiology. Journal of the working groups on cardiac pacing, arrhythmias, and cardiac cellular electrophysiology of the European Society of Cardiology. 2016;18 Suppl 3:iii1-iii79. doi:10.1093/europace/euw244.

4. RAATIKAINEN MJP, ARNAR DO, MERKELY B, NIELSEN JC, HINDRICKS G, HEIDBUCHEL H et al. A Decade of information on the use of cardiac implantable electronic devices and interventional electrophysiological procedures in the European Society of Cardiology Countries: 2017 Report from the European Heart Rhythm Association. Europace: European pacing, arrhythmias, and cardiac electrophysiology. Journal of the working groups on cardiac pacing, arrhythmias, and cardiac cellular electrophysiology of the European Society of Cardiology. 2017;19(suppl_2):ii1-ii90. doi:10.1093/europace/eux258.

5. GARDARSDOTTIR M, SIGURDSSON S, ASPELUND T, ROKITA H, LAUNER LJ, GUDNASON V et al. Atrial fibrillation is associated with decreased total cerebral blood flow and brain perfusion. Europace: European pacing, arrhythmias, and cardiac electrophysiology. Journal of the working groups on cardiac pacing, arrhythmias, and cardiac cellular electrophysiology of the European Society of Cardiology. 2017. doi:10.1093/europace/eux220.

6. FUMAGALLI S, POTPARA TS, BJERREGAARD LARSEN T, HAUGAA KH, DOBREANU D, PROCLEMER A et al. Frailty syndrome: an emerging clinical problem in the everyday management of clinical arrhythmias. The results of the 
European Heart Rhythm Association survey. Europace: European pacing, arrhythmias, and cardiac electrophysiology. Journal of the working groups on cardiac pacing, arrhythmias, and cardiac cellular electrophysiology of the European Society of Cardiology. 2017;19(11):1896-902. doi:10.1093/europace/eux288.

7. GUERRA F, BRAMBATTI M, NIEUWLAAT R, MARCUCCI M, DUDINK E, CRIJNS H et al. Symptomatic atrial fibrillation and risk of cardiovascular events: data from the Euro Heart Survey. Europace: European pacing, arrhythmias, and cardiac electrophysiology. Journal of the working groups on cardiac pacing, arrhythmias, and cardiac cellular electrophysiology of the European Society of Cardiology. 2017;19(12):1922-9. doi:10.1093/europace/eux205.

8. BERGE T, BRYNILDSEN J, LARSSEN HKN, ONARHEIM S, JENSSEN GR, IHLE-HANSEN H et al. Systematic screening for atrial fibrillation in a 65-year-old population with risk factors for stroke: data from the Akershus Cardiac Examination 1950 study. Europace: European pacing, arrhythmias, and cardiac electrophysiology. Journal of the working groups on cardiac pacing, arrhythmias, and cardiac cellular electrophysiology of the European Society of Cardiology. 2017(00):1-7. doi:10.1093/europace/eux293.

9. CLARNETTE JA, BROOKS AG, MAHAJAN R, ELLIOTT AD, TWOMEY DJ, PATHAK RK et al. Outcomes of persistent and long-standing persistent atrial fibrillation ablation: a systematic review and meta-analysis. Europace: European pacing, arrhythmias, and cardiac electrophysiology. Journal of the working groups on cardiac pacing, arrhythmias, and cardiac cellular electrophysiology of the European Society of Cardiology. 2018;20(Fi_3):f366-f76. doi:10.1093/europace/eux297.

10. FIALA M, BULKOVA V, SKNOURIL L, NEVRALOVA R, TOMAN O, JANUSKA J et al. Functional improvement after successful catheter ablation for long-standing persistent atrial fibrillation. Europace: European pacing, arrhythmias, and cardiac electrophysiology. Journal of the working groups on cardiac pacing, arrhythmias, and cardiac cellular electrophysiology of the European Society of Cardiology. 2017;19(11):1781-9. doi:10.1093/europace/euw282.

11. BELLEY-COTE EP, JAFFER I, LAMY A, WHITLOCK RP. Cost effectiveness of LAA closure in patients with AF and contraindications to warfarin: comment. Europace: European pacing, arrhythmias, and cardiac electrophysiology. Journal of the working groups on cardiac pacing, arrhythmias, and cardiac cellular electrophysiology of the European Society of Cardiology. 2017;19(5):882. doi:10.1093/europace/euw072.

12. MIKKELSEN AP, HANSEN ML, OLESEN JB, HVIDTFELDT MW, KARASOY D, HUSTED S et al. Substantial differences in initiation of oral anticoagulant therapy and clinical outcome among non-valvular atrial fibrillation patients treated in inpatient and outpatient settings. Europace: European pacing, arrhythmias, and cardiac electrophysiology. Journal of the working groups on cardiac pacing, arrhythmias, and cardiac cellular electrophysiology of the European Society of Cardiology. 2016;18(4):492-500. doi:10.1093/europace/euv242.

13. TEUNISSEN C, KASSENBERG W, VAN DER HEIJDEN JF, HASSINK RJ, VAN DRIEL VJ, ZUITHOFF NP et al. Fiveyear efficacy of pulmonary vein antrum isolation as a primary ablation strategy for atrial fibrillation: a single-centre cohort study. Europace: European pacing, arrhythmias, and cardiac electrophysiology. Journal of the working groups on cardiac pacing, arrhythmias, and cardiac cellular electrophysiology of the European Society of Cardiology. 2016;18(9):1335-42. doi:10.1093/europace/euv439.

14. HINDRICKS G, SEPEHRI SHAMLOO A, LENARCZYK R, KALARUS Z, ARYA A, KIRCHER S et al. Catheter ablation of atrial fibrillation: current status, techniques, outcomes and challenges. Kardiologia polska. 2018. doi:10.5603/KP.a2018.0216.

15. SIDHU K, TANG A. Modifiable risk factors in atrial fibrillation: The role of alcohol, obesity, and sleep apnea. The Canadian journal of cardiology. 2017;33(7):947-9. doi:10.1016/j.cjca.2017.04.006.

16. MAIRESSE GH, MORAN P, VAN GELDER IC, ELSNER C, ROSENQVIST M, MANT J et al. Screening for atrial fibrillation: A European Heart Rhythm Association (EHRA) consensus document endorsed by the Heart Rhythm Society (HRS), Asia Pacific Heart Rhythm Society (APHRS), and Sociedad Latinoamericana de Estimulacion Cardiaca y Electrofisiologia (SOLAECE). Europace: European pacing, arrhythmias, and cardiac electrophysiology. Journal of the working groups on cardiac pacing, arrhythmias, and cardiac cellular electrophysiology of the European Society of Cardiology. 2017;19(10):1589623. doi:10.1093/europace/eux177.

17. HOBBELT AH, SILAND JE, GEELHOED B, VAN DER HARST P, HILLEGE HL, VAN GELDER IC et al. Clinical, biomarker, and genetic predictors of specific types of atrial fibrillation in a community-based cohort: data of the PREVEND study. Europace: European pacing, arrhythmias, and cardiac electrophysiology. Journal of the working groups on cardiac pacing, arrhythmias, and cardiac cellular electrophysiology of the European Society of Cardiology. 2017;19(2):226-32. doi:10.1093/europace/euw016.

18. CALVO N, RAMOS P, MONTSERRAT S, GUASCH E, COLL-VINENT B, DOMENECH M et al. Emerging risk factors and the dose-response relationship between physical activity and lone atrial fibrillation: a prospective case-control study. Europace: European pacing, arrhythmias, and cardiac electrophysiology. Journal of the working groups on cardiac pacing, arrhythmias, and cardiac cellular electrophysiology of the European Society of Cardiology. 2016;18(1):57-63. doi:10.1093/europace/euv216.

19. PROIETTI M, RAPARELLI V, LAROCHE C, DAN GA, JANION M, POPESCU R et al. Adverse outcomes in patients with atrial fibrillation and peripheral arterial disease: a report from the EURObservational research programme pilot survey on atrial fibrillation. Europace: European pacing, arrhythmias, and cardiac electrophysiology. Journal of the working groups on cardiac pacing, arrhythmias, and cardiac cellular electrophysiology of the European Society of Cardiology. 2017;19(9):1439-48. doi:10.1093/europace/euw169.

20. ALLAN V, HONARBAKHSH S, CASAS JP, WALLACE J, HUNTER R, SCHILLING R et al. Are cardiovascular risk factors also associated with the incidence of atrial fibrillation? A systematic review and field synopsis of 23 factors in 32 populationbased cohorts of 20 million participants. Thrombosis and haemostasis. 2017;117(5):837-50. doi:10.1160/th16-11-0825.

21. NALLIAH CJ, SANDERS P, KALMAN JM. The impact of diet and lifestyle on atrial fibrillation. Current cardiology reports. 2018;20(12):137. doi:10.1007/s11886-018-1082-8.

22. WANG TJ, PARISE H, LEVY D, D'AGOSTINO RB, SR., WOLF PA, VASAN RS et al. Obesity and the risk of new-onset atrial fibrillation. Jama. 2004;292(20):2471-7. doi:10.1001/jama.292.20.2471. 
23. HUXLEY RR, LOPEZ FL, FOLSOM AR, AGARWAL SK, LOEHR LR, SOLIMAN EZ et al. Absolute and attributable risks of atrial fibrillation in relation to optimal and borderline risk factors: the Atherosclerosis Risk in Communities (ARIC) study. Circulation. 2011;123(14):1501-8. doi:10.1161/circulationaha.110.009035.

24. AUNE D, SEN A, SCHLESINGER S, NORAT T, JANSZKY I, ROMUNDSTAD P et al. Body mass index, abdominal fatness, fat mass and the risk of atrial fibrillation: a systematic review and dose-response meta-analysis of prospective studies. European Journal of Epidemiology. 2017;32(3):181-92. doi:10.1007/s10654-017-0232-4.

25. ASAD Z, ABBAS M, JAVED I, KORANTZOPOULOS P, STAVRAKIS S. Obesity is associated with incident atrial fibrillation independent of gender: A meta-analysis. Journal of Cardiovascular Electrophysiology. 2018;29(5):725-32. doi:doi:10.1111/jce.13458.

26. WINKLE RA, MEAD RH, ENGEL G, KONG MH, FLEMING W, SALCEDO J et al. Impact of obesity on atrial fibrillation ablation: Patient characteristics, long-term outcomes, and complications. Heart rhythm. 2017;14(6):819-27. doi:10.1016/ j.hrthm.2017.02.023.

27. GALLAGHER C, HENDRIKS JML, ELLIOTT AD, WONG CX, RANGNEKAR G, MIDDELDORP ME et al. Alcohol and incident atrial fibrillation - A systematic review and meta-analysis. International journal of cardiology. 2017;246:46-52. doi:10.1016/j.ijcard.2017.05.133.

28. PATHAK RK, MIDDELDORP ME, MEREDITH M, MEHTA AB, MAHAJAN R, WONG CX et al. Long-Term Effect of Goal-Directed Weight Management in an Atrial Fibrillation Cohort: A Long-Term Follow-Up Study (LEGACY). Journal of the American College of Cardiology. 2015;65(20):2159-69. doi:10.1016/j.jacc.2015.03.002.

29. TSANG TS, BARNES ME, MIYASAKA Y, CHA SS, BAILEY KR, VERZOSA GC et al. Obesity as a risk factor for the progression of paroxysmal to permanent atrial fibrillation: a longitudinal cohort study of 21 years. European heart journal. 2008;29(18):2227-33.

30. MUNGER TM, DONG Y-X, MASAKI M, OH JK, MANKAD SV, BORLAUG BA et al. Electrophysiological and hemodynamic characteristics associated with obesity in patients with atrial fibrillation. Journal of the American College of Cardiology. 2012;60(9):851-60.

31. GAETA M, BANDERA F, TASSINARI F, CAPASSO L, CARGNELUTTI M, PELISSERO G et al. Is epicardial fat depot associated with atrial fibrillation? A systematic review and meta-analysis. Europace: European pacing, arrhythmias, and cardiac electrophysiology. Journal of the working groups on cardiac pacing, arrhythmias, and cardiac cellular electrophysiology of the European Society of Cardiology. 2017;19(5):747-52.

32. ANSARI MA, MOHEBATI M, POURSADEGH F, FOROUGHIAN M, SHAMLOO AS. Is echocardiographic epicardial fat thickness increased in patients with coronary artery disease? A systematic review and meta-analysis. Electronic physician. 2018;10(9):7249-58. doi:10.19082/7249.

33. LIP GYH, COCA A, KAHAN T, BORIANI G, MANOLIS AS, OLSEN MH et al. Hypertension and cardiac arrhythmias: a consensus document from the European Heart Rhythm Association (EHRA) and ESC Council on Hypertension, endorsed by the Heart Rhythm Society (HRS), Asia-Pacific Heart Rhythm Society (APHRS) and Sociedad Latinoamericana de Estimulacion Cardiaca y Electrofisiologia (SOLEACE). Europace: European pacing, arrhythmias, and cardiac electrophysiology. Journal of the working groups on cardiac pacing, arrhythmias, and cardiac cellular electrophysiology of the European Society of Cardiology. 2017;19(6):891-911. doi:10.1093/europace/eux091.

34. BRANDES A, SMIT MD, NGUYEN BO, RIENSTRA M, VAN GELDER IC. Risk Factor Management in Atrial Fibrillation. Arrhythmia \& electrophysiology review. 2018;7(2):118-27. doi:10.15420/aer.2018.18.2.

35. SCHNABEL RB, YIN X, GONA P, LARSON MG, BEISER AS, MCMANUS DD et al. 50 year trends in atrial fibrillation prevalence, incidence, risk factors, and mortality in the Framingham Heart Study: a cohort study. Lancet (London, England). 2015;386(9989):154-62. doi:10.1016/s0140-6736(14)61774-8.

36. DE BECKER B, DE BORNE PHILIPPE V. Treatment of hypertension to prevent atrial fibrillation. Current pharmaceutical design. 2018. doi:10.2174/1381612825666181127100437.

37. PATHAK RK, MIDDELDORP ME, LAU DH, MEHTA AB, MAHAJAN R, TWOMEY D et al. Aggressive risk factor reduction study for atrial fibrillation and implications for the outcome of ablation: the ARREST-AF cohort study. Journal of the American College of Cardiology. 2014;64(21):2222-31. doi:10.1016/j.jacc.2014.09.028.

38. HEALEY JS, BARANCHUK A, CRYSTAL E, MORILLO CA, GARFINKLE M, YUSUF S et al. Prevention of atrial fibrillation with angiotensin-converting enzyme inhibitors and angiotensin receptor blockers: a meta-analysis. Journal of the American College of Cardiology. 2005;45(11):1832-9.

39. DZESHKA MS, SHANTSILA A, SHANTSILA E, LIP GYH. Atrial Fibrillation and Hypertension. Hypertension (Dallas, Tex: 1979). 2017;70(5):854-61. doi:10.1161/hypertensionaha.117.08934.

40. STAERK L, SHERER JA, KO D, BENJAMIN EJ, HELM RH. Atrial Fibrillation: Epidemiology, Pathophysiology, and Clinical Outcomes. Circulation research. 2017;120(9):1501-17. doi:10.1161/circresaha.117.309732.

41. MEDI C, KALMAN JM, SPENCE SJ, TEH AW, LEE G, BADER I et al. Atrial electrical and structural changes associated with longstanding hypertension in humans: implications for the substrate for atrial fibrillation. J Cardiovasc Electrophysiol. 2011;22(12):1317-24. doi:10.1111/j.1540-8167.2011.02125.x.

42. TADIC M, CUSPIDI C. Type 2 diabetes mellitus and atrial fibrillation: From mechanisms to clinical practice. Archives of cardiovascular diseases. 2015;108(4):269-76. doi:10.1016/j.acvd.2015.01.009.

43. PALLISGAARD JL, SCHJERNING AM, LINDHARDT TB, PROCIDA K, HANSEN ML, TORP-PEDERSEN C et al. Risk of atrial fibrillation in diabetes mellitus: A nationwide cohort study. European journal of preventive cardiology. 2016;23(6):621-7. doi:10.1177/2047487315599892.

44. HUXLEY RR, FILION KB, KONETY S, ALONSO A. Meta-analysis of cohort and case-control studies of type 2 diabetes mellitus and risk of atrial fibrillation. The American journal of cardiology. 2011;108(1):56-62. doi:10.1016/j.amjcard. 2011.03.004. 
45. DUBLIN S, GLAZER NL, SMITH NL, PSATY BM, LUMLEY T, WIGGINS KL et al. Diabetes mellitus, glycemic control, and risk of atrial fibrillation. Journal of general internal medicine. 2010;25(8):853-8. doi:10.1007/s11606-010-1340-y.

46. AUNE D, FENG T, SCHLESINGER S, JANSZKY I, NORAT T, RIBOLI E. Diabetes mellitus, blood glucose and the risk of atrial fibrillation: A systematic review and meta-analysis of cohort studies. Journal of Diabetes and its Complications. 2018;32(5):501-11. doi:10.1016/j.jdiacomp.2018.02.004.

47. YANG PS, KIM TH, UHM JS, PARK S, JOUNG B, LEE MH et al. High plasma level of soluble RAGE is independently associated with a low recurrence of atrial fibrillation after catheter ablation in diabetic patient. Europace: European pacing, arrhythmias, and cardiac electrophysiology. Journal of the working groups on cardiac pacing, arrhythmias, and cardiac cellular electrophysiology of the European Society of Cardiology. 2016;18(11):1711-8. doi:10.1093/europace/euv449.

48. FATEMI O, YURIDITSKY E, TSIOUFIS C, TSACHRIS D, MORGAN T, BASILE J et al. Impact of intensive glycemic control on the incidence of atrial fibrillation and associated cardiovascular outcomes in patients with type 2 diabetes mellitus (from the Action to Control Cardiovascular Risk in Diabetes Study). The American journal of cardiology. 2014;114(8):1217-22. doi:10.1016/j.amjcard.2014.07.045.

49. GOUDIS CA, KORANTZOPOULOS P, NTALAS IV, KALLERGIS EM, LIU T, KETIKOGLOU DG. Diabetes mellitus and atrial fibrillation: Pathophysiological mechanisms and potential upstream therapies. International journal of cardiology. 2015;184:617-22. doi:10.1016/j.ijcard.2015.03.052.

50. RIX TA, JOENSEN AM, RIAHI S, LUNDBYE-CHRISTENSEN S, TJONNELAND A, SCHMIDT EB et al. A U-shaped association between consumption of marine $n-3$ fatty acids and development of atrial fibrillation/atrial flutter-a Danish cohort study. Europace: European pacing, arrhythmias, and cardiac electrophysiology. Journal of the working groups on cardiac pacing, arrhythmias, and cardiac cellular electrophysiology of the European Society of Cardiology. 2014;16(11):1554-61. doi:10.1093/europace/euu019.

51. LARSSON SC, WOLK A. Fish, long-chain omega-3 polyunsaturated fatty acid intake and incidence of atrial fibrillation: A pooled analysis of two prospective studies. Clinical nutrition (Edinburgh, Scotland). 2017;36(2):537-41. doi:10.1016/ j.clnu.2016.01.019.

52. MARTINEZ-GONZALEZ MA, TOLEDO E, AROS F, FIOL M, CORELLA D, SALAS-SALVADO J et al. Extravirgin olive oil consumption reduces risk of atrial fibrillation: the PREDIMED (Prevencion con Dieta Mediterranea) trial. Circulation. 2014;130(1):18-26. doi:10.1161/circulationaha.113.006921.

53. MOSTOFSKY E, BERG JOHANSEN M, TJONNELAND A, CHAHAL HS, MITTLEMAN MA, OVERVAD K. Chocolate intake and risk of clinically apparent atrial fibrillation: the Danish Diet, Cancer, and Health Study. Heart (British Cardiac Society). 2017;103(15):1163-7. doi:10.1136/heartjnl-2016-310357.

54. LARSSON SC, DRCA N, JENSEN-URSTAD M, WOLK A. Chocolate consumption and risk of atrial fibrillation: Two cohort studies and a meta-analysis. American heart journal. 2018;195:86-90. doi:10.1016/j.ahj.2017.09.013.

55. MOSTOFSKY E, JOHANSEN MB, LUNDBYE-CHRISTENSEN S, TJONNELAND A, MITTLEMAN MA, OVERVAD K. Risk of atrial fibrillation associated with coffee intake: Findings from the Danish Diet, Cancer, and Health study. European journal of preventive cardiology. 2016;23(9):922-30. doi:10.1177/2047487315624524.

56. DI CASTELNUOVO A, COSTANZO S, BONACCIO M, RAGO L, DE CURTIS A, PERSICHILLO M et al. Moderate alcohol consumption is associated with lower risk for heart failure but not atrial fibrillation. JACC Heart failure. 2017;5(11):837-44. doi:10.1016/j.jchf.2017.08.017.

57. DJOUSSE L, LEVY D, BENJAMIN EJ, BLEASE SJ, RUSS A, LARSON MG et al. Long-term alcohol consumption and the risk of atrial fibrillation in the Framingham Study. The American journal of cardiology. 2004;93(6):710-3. doi:10.1016/ j.amjcard.2003.12.004.

58. LARSSON SC, DRCA N, WOLK A. Alcohol consumption and risk of atrial fibrillation: a prospective study and dose-response meta-analysis. Journal of the American College of Cardiology. 2014;64(3):281-9. doi:10.1016/j.jacc.2014.03.048.

59. MESQUITA J, FERREIRA AM, CAVACO D, MOSCOSO COSTA F, CARMO P, MARQUES H et al. Development and validation of a risk score for predicting atrial fibrillation recurrence after a first catheter ablation procedure - ATLAS score. Europace: European pacing, arrhythmias, and cardiac electrophysiology. Journal of the working groups on cardiac pacing, arrhythmias, and cardiac cellular electrophysiology of the European Society of Cardiology. 2018;20(Fi_3):f428-f35. doi:10.1093/europace/eux265.

60. BEBAROVA M, HORAKOVA Z, KULA R. Addictive drugs, arrhythmias, and cardiac inward rectifiers. Europace: European pacing, arrhythmias, and cardiac electrophysiology. Journal of the working groups on cardiac pacing, arrhythmias, and cardiac cellular electrophysiology of the European Society of Cardiology. 2017;19(3):346-55. doi:10.1093/europace/euw071.

61. ALBERTSEN IE, OVERVAD TF, LIP GY, LARSEN TB. Smoking, atrial fibrillation, and ischemic stroke: a confluence of epidemics. Curr Opin Cardiol. 2015;30(5):512-7. doi:10.1097/hco.0000000000000205.

62. WATANABE I. Smoking and risk of atrial fibrillation. Elsevier; 2018.

63. AUNE D, SCHLESINGER S, NORAT T, RIBOLI E. Tobacco smoking and the risk of atrial fibrillation: A systematic review and meta-analysis of prospective studies. European journal of preventive cardiology. 2018;25(13):1437-51. doi:10.1177/2047487318780435.

64. O'NEAL WT, QURESHI WT, JUDD SE, MCCLURE LA, CUSHMAN M, HOWARD VJ et al. Environmental tobacco smoke and atrial fibrillation: The reasons for geographic and racial differences in stroke (REGARDS) study. Journal of occupational and environmental medicine. 2015;57(11):1154-8. doi:10.1097/jom.0000000000000565.

65. DIXIT S, PLETCHER MJ, VITTINGHOFF E, IMBURGIA K, MAGUIRE C, WHITMAN IR et al. Secondhand smoke and atrial fibrillation: Data from the Health eHeart Study. Heart rhythm. 2016;13(1):3-9. doi:10.1016/j.hrthm.2015.08.004.

66. SABZWARI SRA, GARG L, LAKKIREDDY D, DAY J. Ten lifestyle modification approaches to treat atrial fibrillation. Cureus. 2018;10(5):e2682. doi:10.7759/cureus.2682. 
67. GOETTE A, LENDECKEL U, KUCHENBECKER A, BUKOWSKA A, PETERS B, KLEIN HU et al. Cigarette smoking induces atrial fibrosis in humans via nicotine. Heart (British Cardiac Society). 2007;93(9):1056-63. doi:10.1136/ hrt.2005.087171.

68. WATANABE H, TANABE N, YAGIHARA N, WATANABE T, AIZAWA Y, KODAMA M. Association between lipid profile and risk of atrial fibrillation. Circulation journal: official journal of the Japanese Circulation Society. 2011;75(12):2767-74.

69. RIENSTRA M, HOBBELT AH, ALINGS M, TIJSSEN JGP, SMIT MD, BRUGEMANN J et al. Targeted therapy of underlying conditions improves sinus rhythm maintenance in patients with persistent atrial fibrillation: results of the RACE 3 trial. Eur Heart J. 2018;39(32):2987-96. doi:10.1093/eurheartj/ehx739.

70. FANG WT, LI HJ, ZHANG H, JIANG S. The role of statin therapy in the prevention of atrial fibrillation: a meta-analysis of randomized controlled trials. British journal of clinical pharmacology. 2012;74(5):744-56. doi:10.1111/j.13652125.2012.04258.x.

71. VAN GELDER IC, HOBBELT AH, BRUGEMANN J, RIENSTRA M. Time to implement fitness and reduction of fatness in atrial fibrillation therapy. Europace: European pacing, arrhythmias, and cardiac electrophysiology. Journal of the working groups on cardiac pacing, arrhythmias, and cardiac cellular electrophysiology of the European Society of Cardiology. 2017;19(4):513-4. doi:10.1093/europace/euw287.

72. PROIETTI M, BORIANI G, LAROCHE C, DIEMBERGER I, POPESCU MI, RASMUSSEN LH et al. Self-reported physical activity and major adverse events in patients with atrial fibrillation: a report from the EURObservational Research Programme Pilot Survey on Atrial Fibrillation (EORP-AF) General Registry. Europace: European pacing, arrhythmias, and cardiac electrophysiology. Journal of the working groups on cardiac pacing, arrhythmias, and cardiac cellular electrophysiology of the European Society of Cardiology. 2017;19(4):535-43. doi:10.1093/europace/euw150.

73. ELLIOTT AD, MAATMAN B, EMERY MS, SANDERS P. The role of exercise in atrial fibrillation prevention and promotion: Finding optimal ranges for health. Heart rhythm. 2017;14(11):1713-20. doi:10.1016/j.hrthm.2017.07.001.

74. FLANNERY MD, KALMAN JM, SANDERS P, LA GERCHE A. State of the art review: atrial fibrillation in athletes. Heart, lung \& circulation. 2017;26(9):983-9. doi:10.1016/j.hlc.2017.05.132.

75. DRCA N, WOLK A, JENSEN-URSTAD M, LARSSON SC. Physical activity is associated with a reduced risk of atrial fibrillation in middle-aged and elderly women. Heart (British Cardiac Society). 2015;101(20):1627-30. doi:10.1136/heartjnl2014-307145.

76. MITTAL S. Physical Activity and Incidence of Atrial Fibrillation in Older Adults: The Cardiovascular Health Study. Journal of atrial fibrillation. 2008;1(3):132. doi:10.4022/jafib.132.

77. YANG Y, HAN X, CHEN Y, GAO L, YIN X, LI H et al. Association between modifiable lifestyle and the prevalence of atrial fibrillation in a Chinese population: Based on the cardiovascular health score. Clinical cardiology. 2017;40(11):1061-7. doi:10.1002/clc.22771.

78. PARK J, KYOUNG AK. 136-75: Gender difference of life style patterns including smoking, alcohol, and physical activity related to new onset atrial fibrillation: A nationwide cohort study in Korea. EP Europace. 2016;18(suppl_1):i109-i. doi:10.1093/europace/18.suppl_1.i109a.

79. RICCI C, GERVASI F, GAETA M, SMUTS CM, SCHUTTE AE, LEITZMANN MF. Physical activity volume in relation to risk of atrial fibrillation. A non-linear meta-regression analysis. European journal of preventive cardiology. 2018;25(8):857-66. doi:10.1177/2047487318768026.

80. SEPEHRI SHAMLOO A, ARYA A, DAGRES N, HINDRICKS G. Exercise and atrial fibrillation: some good news and some bad news. GMJ. 2018;7:e1401. doi:10.22086/gmj.v0i0.1401.

81. VIDAL A, AGORRODY V, ABREU R, VIANA P, DODERA A, VIDAL L. Vagal third-degree atrioventricular block in a highly trained endurance athlete. Europace: European pacing, arrhythmias, and cardiac electrophysiology. Journal of the working groups on cardiac pacing, arrhythmias, and cardiac cellular electrophysiology of the European Society of Cardiology. 2017;19(11):1863. doi:10.1093/europace/eux045.

82. LINZ D, HOHL M, VOLLMAR J, UKENA C, MAHFOUD F, BOHM M. Atrial fibrillation and gastroesophageal reflux disease: the cardiogastric interaction. Europace: European pacing, arrhythmias, and cardiac electrophysiology. Journal of the working groups on cardiac pacing, arrhythmias, and cardiac cellular electrophysiology of the European Society of Cardiology. 2017;19(1):16-20. doi:10.1093/europace/euw092.

83. EL-BATTRAWY I, LANG S, ZHOU X, BORGGREFE M, AKIN I. The link between atrial fibrillation and hereditary channelopathies. Europace: European pacing, arrhythmias, and cardiac electrophysiology. Journal of the working groups on cardiac pacing, arrhythmias, and cardiac cellular electrophysiology of the European Society of Cardiology. 2018;20(11):1872. doi:10.1093/europace/euy109.

84. SENTURK T, XU H, PUPPALA K, KRISHNAN B, SAKAGUCHI S, CHEN LY et al. Cardiac pauses in competitive athletes: a systematic review examining the basis of current practice recommendations. Europace: European pacing, arrhythmias, and cardiac electrophysiology. Journal of the working groups on cardiac pacing, arrhythmias, and cardiac cellular electrophysiology of the European Society of Cardiology. 2016;18(12):1873-9. doi:10.1093/europace/euv373.

85. SEPEHRI SHAMLOO A, ARYA A, DAGRES N, HINDRICKS G. Sleep disorders and atrial fibrillation: current situation and future directions. GMJ. 2018;7:e1416. doi:10.22086/gmj.v0i0.1416.

86. ZHAO E, CHEN S, DU Y, ZHANG Y. Association between sleep apnea hypopnea syndrome and the risk of atrial fibrillation: A meta-analysis of cohort study. BioMed research international. 2018;2018:5215868. doi:10.1155/2018/5215868.

87. YOUSSEF I, KAMRAN H, YACOUB M, PATEL N, GOULBOURNE C, KUMAR S et al. Obstructive sleep apnea as a risk factor for atrial fibrillation: A meta-analysis. Journal of sleep disorders \& therapy. 2018;7(1). doi:10.4172/2167-0277.1000282.

88. MAY AM, BLACKWELL T, STONE PH, STONE KL, CAWTHON PM, SAUER WH et al. Central Sleep-disordered Breathing Predicts Incident Atrial Fibrillation in Older Men. American journal of respiratory and critical care medicine. 2016;193(7):783-91. doi:10.1164/rccm.201508-1523OC. 
89. kwon y, gharib sa, biggs ml, jacobs DR, Jr., ALONSO A, DUPREZ D et al. Association of sleep characteristics with atrial fibrillation: the Multi-Ethnic Study of Atherosclerosis. Thorax. 2015;70(9):873-9. doi:10.1136/thoraxjnl-2014-206655.

90. GHAZI L, BENNETT A, PETROV ME, HOWARD VJ, SAFFORD MM, SOLIMAN EZ et al. Race, sex, age, and regional differences in the association of obstructive sleep apnea with atrial fibrillation: reasons for geographic and racial differences in stroke study. Journal of clinical sleep medicine: JCSM: official publication of the American Academy of Sleep Medicine. 2018;14(9):1485-93. doi:10.5664/jcsm.7320.

91. DENG F, RAZA A, GUO J. Treating obstructive sleep apnea with continuous positive airway pressure reduces risk of recurrent atrial fibrillation after catheter ablation: a meta-analysis. Sleep medicine. 2018;46:5-11. doi:10.1016/j.sleep.2018.02.013.

92. LAU DH, NATTEL S, KALMAN JM, SANDERS P. Modifiable risk factors and atrial fibrillation. Circulation. 2017;136(6):583-96. doi:10.1161/circulationaha.116.023163.

93. GAO M, ZHANG L, SCHERLAG BJ, HUANG B, STAVRAKIS S, HOU YM et al. Low-level vagosympathetic trunk stimulation inhibits atrial fibrillation in a rabbit model of obstructive sleep apnea. Heart rhythm. 2015;12(4):818-24. doi:10.1016/j.hrthm.2014.12.024.

Received December 12, 2018 